\title{
Complutum
}

ISSN: 1131-6993

\section{Alfarería y metalurgia en el Suroeste de la Península Ibérica durante el III Milenio A.N.E.: elecciones tecnológicas en la manufactura de instrumentos cerámicos vinculados al proceso metalúrgico}

\author{
Nuno Inácio ${ }^{1}$; Francisco Nocete ${ }^{2}$; José Miguel Nieto ${ }^{3}$; Moisés Rodríguez Bayona ${ }^{4}$
}

Recibido: 25 de mayo de 2016 / Aceptado: 3 de agosto de 2017

Resumen. En este trabajo se evalúan las primeras etapas metalúrgicas del Suroeste de la Península Ibérica desde una nueva perspectiva teórica y metodológica: los procesos tecnológicos empleados en la manufactura de instrumentos cerámicos vinculados a la metalurgia. De esta forma se pretende analizar el grado de interacción entre la actividad alfarera y la metalúrgica, y de qué manera la introducción de esta última influenció los modos de fabricar vasijas cerámicas. En este sentido, mediante el análisis arqueométrico de crisoles, toberas y vasijas de reducción documentadas en tres contextos arqueológicos del III Milenio A.N.E. (Cabezo Juré, La Junta y Valencina de la Concepción), se explora el concepto de elección tecnológica como marco teórico, focalizando el estudio de las primeras fases del proceso de fabricación de estos instrumentos cerámicos. Los resultados aportados ponen de manifiesto la existencia de diferencias significativas en los procesos tecnológicos empleados en la manufactura de las diferentes vasijas metalúrgicas, principalmente cuando las comparamos con los recipientes de carácter doméstico.

Palabras clave: cerámica metalúrgica; crisoles; toberas; tecnología; arqueometría; metalurgia del cobre; III Milenio A.N.E.

\section{[en] Pottery and Metallurgical Activity in Southwest of the Iberian Peninsula during III Milennium B.C.E.: Technological choices in the Manufacture of Ceramic Instruments associated to the Metallurgical Process}

\begin{abstract}
In this work the first metallurgical stages of the Southwest of the Iberian Peninsula are evaluated from a new theoretical and methodological approach: the technological processes used in the manufacture of metallurgical ceramics. From this way it aims to analyse the degree of interaction between the pottery and metallurgical activity, and how the introduction of the latter influenced the ways of making ceramic vessels. In this sense, by archaeometric analysis of metallurgical ceramics of three archaeological contexts from III Millennium B.C.E. (Cabezo Juré, La Junta and Valencina de la Concepción), the concept of technological choice as a theoretical framework is explored, focusing on the study of the early stages of the manufacturing process of these instruments. The results provided show the existence of significant differences in the technological processes used in the manufacture of various metallurgical ceramics, especially when compared with domestic vessels. tance of legal fictions and reaches the substance of the law as a western and westernized set of concepts, logics.
\end{abstract}

Keywords: Metallurgical ceramics; Crucibles: Tuyères; Technology; Archaeometry; Copper Metallurgy; III Milennium B.C.E.

Sumario. 1. Introducción. 2. Los contextos metalúrgicos en el Suroeste de la Península Ibérica. 3. Las primeras cerámicas metalúrgicas: crisoles, vasijas de reducción y toberas. 4. Identificación de las elecciones tecnológicas en sus contextos. 4.1. La Junta. 4.2. Cabezo Juré. 4.3. Valencina de la Concepción. 5. Discusión. 6. Conclusión.

\footnotetext{
Universidad de Huelva, Facultad de Humanidades, Departamento de Historia I (España)

E-mail: nuno.inacio@dhis1.uhu.es

2 Universidad de Huelva, Facultad de Humanidades, Departamento de Historia I (España)

E-mail: nocete@dhis1.uhu.es

3 Universidad de Huelva, Facultad de Ciencias Experimentales, Departamento de Geología (España)

E-mail: jmnieto@dgeo.uhu.es

4 Universidad de Huelva, Facultad de Humanidades, Departamento de Historia I (España)

E-mail: moises.rodriguez@dhis1.uhu.es
} 
Cómo citar: Inácio, N et al. (2017): Alfarería y metalurgia en el Suroeste de la Península Ibérica durante el III Milenio A.N.E.: elecciones tecnológicas en la manufactura de instrumentos cerámicos vinculados al proceso metalúrgico. Complutum, 28(1): 51-69.

\section{Introducción}

En los últimos años se viene enfatizando la necesidad de evaluar los mecanismos de compatibilidad y complementariedad entre diferentes actividades artesanales desarrolladas por las sociedades pretéritas. En lo que concierne a la alfarería y la metalurgia, las investigaciones llevadas a cabo en el Suroeste de Península Ibérica han puesto de manifiesto que estas actividades comparten varios aspectos de sus procesos de producción, distribución y consumo, desde luego los contextos espaciales y los agentes sociales, pero también algunos instrumentos, herramientas, procedimientos tecnológicos y saberes técnicos (Inácio 2015).

Las técnicas, las herramientas y los conocimientos empleados en las diferentes etapas del proceso productivo tienen implicaciones en la definición de los modelos de organización socioeconómica de la metalurgia del cobre. Así pues, resulta especialmente sugerente la gran importancia que presentan los elementos cerámicos involucrados en la actividad metalúrgica, no sólo en la evaluación de su lugar específico en la cadena operativa sino también en las técnicas empleadas durante el proceso de producción como instrumentos metalúrgicos. El análisis de estos elementos es imprescindible en la evaluación del grado de la interacción técnica y social entre la alfarería y la metalurgia.

En términos generales, los estudios sobre cerámicas metalúrgicas han estado orientados a dos ámbitos de análisis (Martinón-Torres y Rehren 2014). Un primer ámbito ha enfocado el análisis de los restos de escorificaciones adheridas a las paredes de los crisoles y vasijas de reducción, de cara a evaluar el proceso metalúrgico, las temperaturas alcanzadas y la funcionalidad de estas herramientas. Un segundo aspecto de análisis, ha sido objeto de menor atención por parte de los investigadores, a pesar de algunas aportaciones recientes (Inácio et al. 2010; Polvorinos et al. 2010). Se trata del análisis de sus pastas, al objeto de comprender los procesos de fabricación de estos instrumentos, los criterios de selección de las ma- terias primas y su posible tratamiento de cara a soportar los elevados gradientes térmicos a que estuvieron sometidos estos recipientes.

Los instrumentos cerámicos vinculados a la metalurgia son, ante de todo, productos que han resultado de un conjunto de acciones, gestos y opciones tecnológicas de los agentes de la producción. En los últimos años, el concepto de elección tecnológica ha asumido una dimensión teórica en el contexto de los estudios sobre la técnica y los procesos tecnológicos adoptados en los diferentes niveles de la cadena operativa (Sillar y Tite 2000). Durante toda la secuencia, los gestos y comportamientos humanos son el reflejo de formas o estilos de trabajar que pueden constituir actos conscientes o aleatorios. Así pues, las posibles repercusiones de las decisiones técnicas y la consciencia de la previsibilidad de los resultados (por ejemplo, los conocimientos de las propiedades de los materiales empleados), van a definir el proceso de producción, el aspecto final del recipiente, sus cualidades, sus propiedades y el uso social del mismo.

En relación a la cerámica metalúrgica, habría que enfatizar que determinadas selecciones tecnológicas pueden haber constituido actos conscientes con vista a incrementar determinadas propiedades o favorecer determinadas características de estos elementos, por lo que el análisis de la cadena operativa puede adquirir gran importancia, ya que permite abordar la interacción entre los sujetos sociales de la producción, la materialidad y las técnicas empleadas en su transformación. Es decir, se trata de identificar si existen o no determinadas elecciones tecnológicas o procesos de producción que puedan estar directamente relacionados con determinados conocimientos técnicos.

En los últimos años, desde la observación Etnoarqueológica, la Arqueología Experimental o la Arqueometría, varios autores han orientado su análisis teórico y metodológico hacia las características y propiedades de los productos y de las materias primas utilizadas en la manufactura de vasijas de cerámica en función de sus usos sociales concretos, de cara a evaluar empíricamente los conocimientos 
tecnológicos de los antiguos ceramistas. Así por ejemplo, uno de los temas centrales en la investigación ha estado orientado al análisis de las propiedades de los diferentes tipos de desgrasantes en relación al incremento de la resistencia al choque térmico, resistencia al choque mecánico o la conductividad térmica, entre otros (Allegretta et al. 2014; Muller et al. 2014; Tite et al. 2001).

En este trabajo se explora el concepto de elección tecnológica desde la reconstrucción de la cadena operativa asociada a la manufactura de instrumentos cerámicos vinculados al proceso metalúrgico (crisoles, vasijas de reducción y toberas) en tres contextos del Suroeste de la Península Ibérica pertenecientes al III Milenio A.N.E. Para ello se ha diseñado un programa metodológico de análisis petrográfico, mineralógico y químico sobre estos elementos con el objeto de no sólo comparar los procesos de producción de los diferentes tipos de recipientes metalúrgicos, en lo que respecta a las estrategias de aprovisionamiento, selección de la materia prima y su tratamiento, sino que se ha pretendido, además, evaluar la existencia de posibles procesos diferenciados de manufactura en relación a la cerámica de uso doméstico.

\section{Los contextos metalúrgicos en el Suroeste de la Península Ibérica}

El concepto y la percepción de la minería y metalurgia prehistórica, de su magnitud y efectos, y su desarrollo cronológico, tecnológico y social, vienen siendo modificados desde la evaluación y análisis de los modelos de organización de la actividad metalúrgica en varios asentamientos del Suroeste de la Península Ibérica como Cabezo Juré y La Junta, en plena Faja Pirítica Ibérica, o Valencina de la Concepción en el Valle del Guadalquivir (Fig. 1).

El yacimiento de Cabezo Juré (Nocete 2004 y 2006), situado a tan sólo $3 \mathrm{Km}$ al sureste del distrito minero de Tharsis, se ubica en plena Faja Pirítica Ibérica, una de las provincias metalogenéticas más importantes del mundo, con una de las mayores concentraciones de sulfuros masivos. Su ubicación en una posición dominante en el territorio minero del entorno, señala una estrategia locacional donde se privilegió una conducta defensiva, permitiendo el control visual de un amplio territorio de explotación, en especial, el control de las princi- pales mineralizaciones de cobre de la región: Tharsis, Almagrera y La Lapilla. Las excavaciones arqueológicas que se han realizado en el yacimiento de Cabezo Juré han documentado un contexto arqueológico que fue el efecto de una comunidad tecnológica y socialmente especializada en la metalurgia del cobre, con dataciones de radiocarbono que lo adscriben al proceso histórico del III Milenio ANE (Nocete et al. 2011). Esta especialización se manifiesta en la masiva presencia de minerales de cobre (malaquita, azurita, cuprita, tenorita, calcosina y covellina), instrumentos de producción (hornos, crisoles, toberas, etc.) y transformación metalúrgica (martillos, moldes, etc.), así como desechos (escorias) y manufacturas metálicas en los distintos procesos de su elaboración (hachas, cuchillos, sierras, etc.), frente a la ausencia de instrumentos y actividades que puedan señalar alguna intervención agrícola orientada a la producción de alimentos. En este sentido, el registro polínico no sólo confirma la ausencia de taxones cerealísticos, sino que, además, documenta un proceso de deforestación que coincide con el constante y progresivo consumo de madera para la alimentación de los hornos de reducción de mineral y fundición de metal (Nocete 2001 y 2006).

Paralelamente, el análisis del registro arqueológico del asentamiento de La Junta, un pequeño poblado ubicado a tan sólo $25 \mathrm{~km}$ de Cabezo Juré, señala la existencia de una conducta económica distinta, caracterizada por la ausencia de prácticas agrícolas o pastoriles, frente a las actividades de caza que implican el aporte de más de $80 \%$ de las proteínas consumidas. Asimismo, varios sectores artesanales están representados por una amplia gama de productos que cubrieron las necesidades de consumo pero donde ninguno alcanzó un nivel de especialización productiva. Es el caso de la metalurgia, que se desarrolló como una actividad limitada al trabajo final de producción y reciclaje de productos, testado mediante la presencia de crisoles y toberas destinados a procesar nódulos de cobre cuyo origen, los análisis de isótopos de plomo sitúan en las mineralizaciones próximas de la Faja Pirítica (Nocete 2008). Esta peculiar configuración económica de La Junta, regida por la ausencia de actividades de producción destinadas a la subsistencia, lo convierte en un centro donde dominan las actividades de consumo, señala un nivel de dependencia económica sólo explicable con la prestación de un servicio de control estratégico 


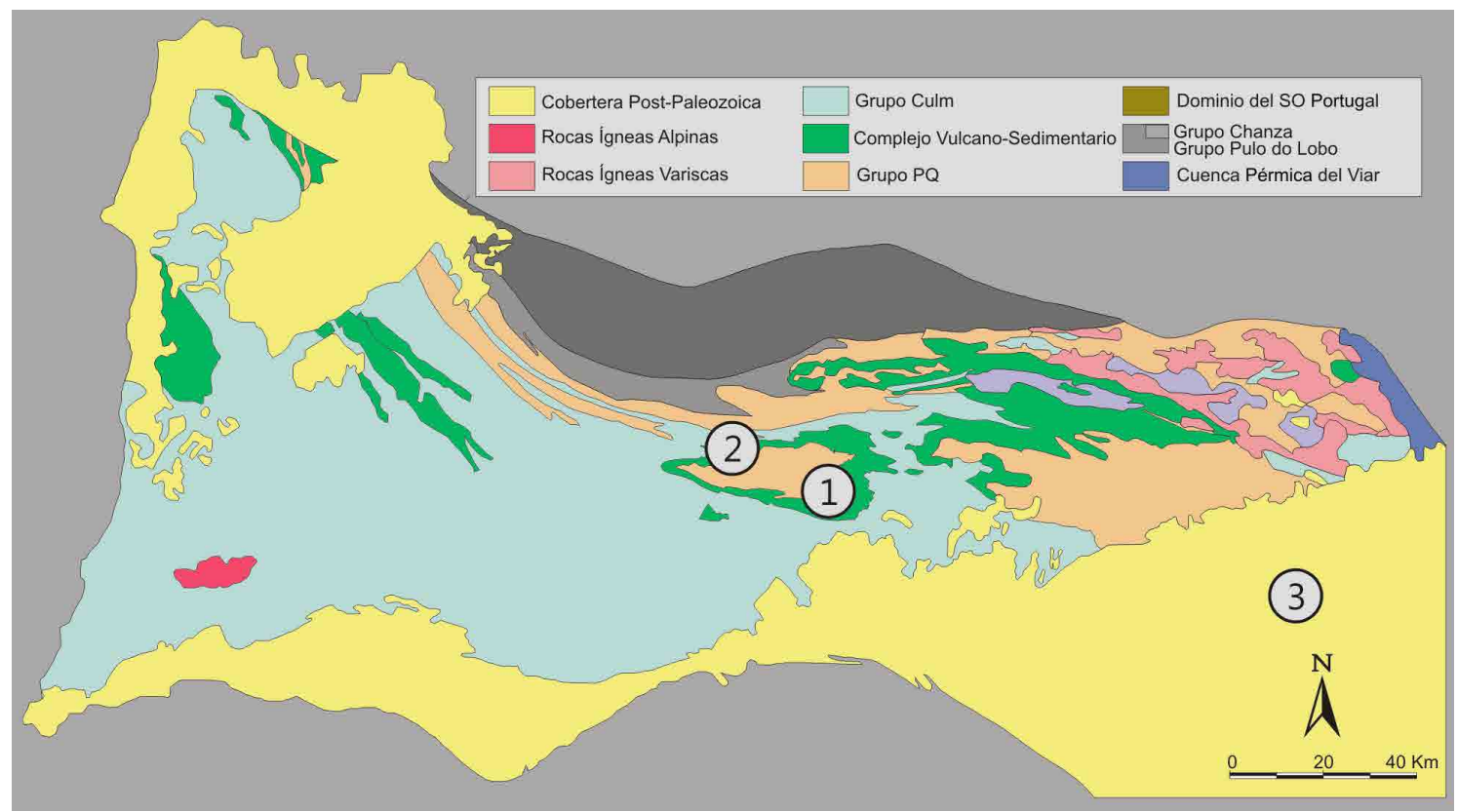

Figura 1. Localización de los asentamientos estudiados en este trabajo (1 - Cabezo Juré; 2 - La Junta; 3 Valencina de la Concepción) en el mapa geológico esquemático del Suroeste de la Península Ibérica.

del territorio como contrapartida, especialización funcional que se relaciona con una compleja ordenación territorial articulada alrededor de la minería y metalurgia del cobre. Por tanto, en este área geográfica se desarrolló un complejo proyecto minero desde asentamientos localizados en las topografías dominantes junto a mineralizaciones de cobre (Cabezo Juré, Castillito de Cabezas del Pasto, etc.), y secundado por pequeños asentamientos dependientes (La Junta), que dominando las vías de comunicación y puntos de paso, determinaron la existencia de una organización territorial dotada de un elevado grado de complejidad.

El salto desde el Faja Pirítica onubense hasta el bajo valle del Guadalquivir, con Valencina de la Concepción como referente principal, se justifica por la magnitud de los contextos metalúrgicos documentados en los últimos años. Las intervenciones arqueológicas realizadas en el sureste del yacimiento, en una área delimitada por un sistema de fosos cuyo trazado principal (E-O) define tanto el límite sur del asentamiento como separa este área de la del ámbito funerario, ha permitido identificar un conjunto de unidades estructurales agrupadas en cuatro sectores divididos por fosos perpendiculares (N-S) de menor entidad al principal. Un conjunto significativo de estas estructuras, con evidencias de fuertes termoalteraciones en sus paredes y bases, se encontraba asociada a minerales, escorias y a varias herramientas vinculadas a la actividad metalúrgica (toberas, crisoles, molinos, percutores, productos de cobre, etc.). Estos contextos definen, por tanto, una configuración espacial y económica que evidencian a la actividad metalúrgica como el único sector productivo de este área del asentamiento. Su especialización, dependencia subsistencial y delimitación espacial, nos permiten interpretar su diseño como el de un extenso barrio artesanal. La evaluación y análisis de la actividad metalúrgica en Valencina de la Concepción ha permitido la definición de un complejo sistema de producción, donde los indicadores arqueológicos señalan un nivel diferenciado y superior de desarrollo tecnológico respecto a sitios de su misma cronología (Nocete et al. 2008).

La selección de estos tres contextos con inequívocos registros de actividades metalúrgicas y donde su organización técnica y social muestran escalas distintas, permitía, además, evaluar si las distintas elecciones tecnológicas estaban o no determinadas por la organización y escala de la propia actividad metalúrgica, es decir, si el grado de especialización del trabajo metalúrgico tenía o no repercusiones en las 
elecciones y en los procedimientos técnicos empleados en la manufactura de crisoles, vasijas de reducción y toberas.

\section{Las primeras cerámicas metalúrgicas: crisoles, vasijas de reducción y toberas}

Se denomina crisol, a los pequeños recipientes de cerámica destinados a fundir el metal previamente reducido en hornos, para su posterior vertido en un molde cuando se encuentre en estado líquido. Los crisoles identificados en contextos metalúrgicos del III Milenio A.N.E del Suroeste Peninsular exhiben las paredes fuertemente alteradas por los altos gradientes térmicos a los que han estado sometidos, y a menudo escorificaciones adheridas en las superficies internas y en el borde. Presentan en general una morfología de tendencia rectangular, oval u oblonga, con $16 / 18 \mathrm{~cm}$ de longitud máxima por $6 / 8 \mathrm{~cm}$ de anchura máxima, con espesas paredes, superiores a $1 \mathrm{~cm}$, que no exceden los $3 \mathrm{~cm}$ de altura (Fig. 2). Recientemente, en los contextos metalúrgicos de Valencina de la Concepción, ha sido posible identificar también crisoles circulares (Fig. 3), con bases planas y paredes que pueden alcanzar los $5 \mathrm{~cm}$ de altura (Inácio et al. 2010). Así, y aunque desconocidos en otros yacimientos peninsulares, estos ejemplares parecen representar los prototipos más antiguos de los crisoles circulares comunes en los contextos del II Milenio A.N.E., similares, por ejemplo, a los registrados en el yacimiento metalúrgico de Peñalosa (Moreno 2000).

A pesar del elevado grado de fragmentación que habitualmente los crisoles presentan, los contextos de Cabezo Juré han ofrecido dos ejemplares completos, donde se ha podido calcular su volumen en $110 \mathrm{~cm}^{3}$ y $170 \mathrm{~cm}^{3}$ (Nocete 2004). En Valencina de la Concepción también fue posible recuperar algunos crisoles casi completos, cuya capacidad puede alcanzar hasta los $300 \mathrm{~cm}^{3}$ (Inácio et al. 2010). Estos ejemplares de Valencina de la Concepción podrían soportar una carga superior a $2,5 \mathrm{Kg}$, suficiente para la fabricación de algunas hachas identificadas en el mismo yacimiento (López y Parruelo 2013) o, y de una sola colada, la producción de cientos de punzones como los registrados en este mismo contexto arqueológico (Bayona 2008).

No obstante, además de los casos tratados en este trabajo, la presencia de crisoles se en- cuentra bien documentada en otros contextos del Suroeste. En el Sur de Portugal son conocidos algunos ejemplares de crisoles de tendencia rectangular oblonga en varios yacimientos como João Marques, Santa Justa, São Brás, Três Moinhos, Castelo Velho de Safara o Porto Mourão (Gonçalves 1989; Soares et al. 1994), $\mathrm{y}$ en la provincia de Badajoz hay registros de crisoles en La Pijotilla (Hunt 2003), San Blas (Hunt et al. 2009; Polvorinos et al. 2010) o Sierrecilla (Cruz et al. 2006).

En otro sentido, y a pesar de su normalización tipológica, los crisoles cerámicos pueden presentar pequeñas variaciones. Así por ejemplo, en la Extremadura portuguesa, además de las formas referidas, algunos ejemplares presentan contornos de tendencia elipsoidal y fondo convexo (Cardoso y Caninas 2010), equipados o no de pequeños pies cilíndricos para mejorar la sujeción horizontal, como serían los ejemplos hallados en Vila Nova de São Pedro (Soares 2005) y Zambujal (Harning et al. 2010; Muller et al. 2007). Al parecer, sólo durante el II Milenio A.N.E. los crisoles tienden a evolucionar hacía morfologías más complejas, en algunos casos dotados con pico vertedero para facilitar el vaciado correcto del metal fundido en los moldes y sistema de sujeción o enmangue (Renzi 2010; Simón 1996).

Con el objeto de comprender la funcionalidad de estas vasijas y evaluar su lugar en el proceso de obtención de productos de cobre, la investigación arqueometalúrgica ha centrado principalmente su interés en el estudio de las escorificaciones adheridas a los crisoles. En este sentido, el análisis de los crisoles de

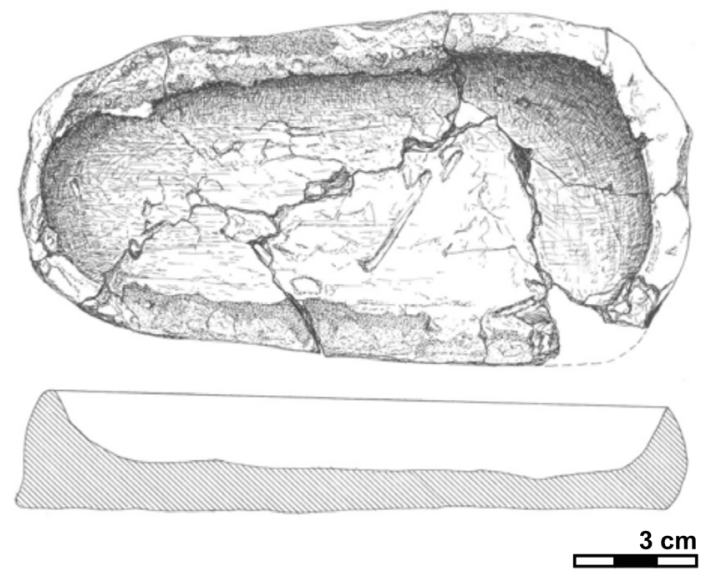

Figura 2. Crisol completo documentado de Cabezo Juré. 

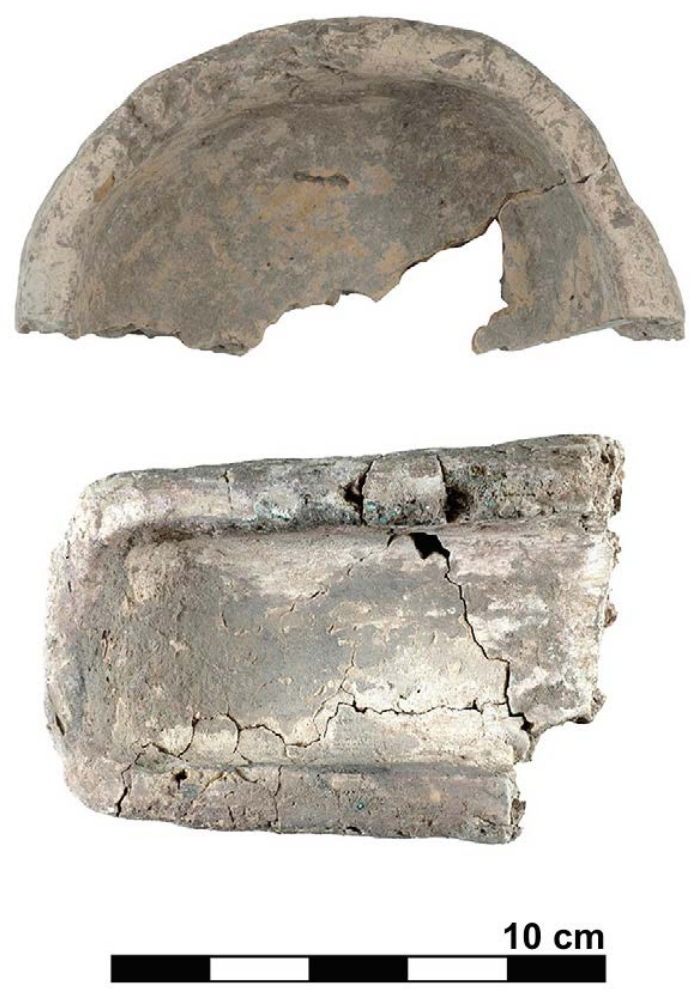

Figura 3. Crisoles documentados en el Barrio Metalúrgico de Valencina de la Concepción.

Cabezo Juré ha permitido evaluar su funcionalidad en el proceso de producción metalúrgica. El estudio químico y mineralógico sugiere que los crisoles han estado asociados a labores y tareas de refino del cobre (fundición) para su posterior vertido en moldes, descartando, por tanto, su utilización como instrumentos para la reducción de minerales (Sáez et al. 2003). A pesar de estas evidencias, algunos autores siguen refiriéndose a estos elementos cerámicos como bandejas oblongas manufacturados específicamente para la reducción de minerales (Renzi 2010: 132), otorgándoles una funcionalidad similar a las denominadas vasijas de reducción.

En ciertos aspectos, esta dicotomía entre crisoles y vasijas de reducción ha centrado el debate sobre los inicios de la metalurgia del cobre en la Península Ibérica. El estudio de los fragmentos cerámicos hallados en el yacimiento de Perales del Río (Getafe, Madrid) llevó a Salvador Rovira y colaboradores (1989) a proponer un modelo metalúrgico con base en la utilización de las denominadas vasijas horno (Gómez 1996; Rovira y Ambert 2002; Rovira 2006), designación procedente del término anglosajón crucible furnace, aunque en trabajos más recientes los autores han abandonado esta denominación, optando por el término de vasija de reducción (Rovira y Ambert 2002), por ser más adecuado para las tareas desarrolladas en su interior.

La tecnología de las vasijas de reducción corresponde genéricamente a la (re)utilización de recipientes de cerámica en las que se introducía directamente el mineral finamente triturado, cubierto por una espesa capa de carbón para asegurar un ambiente reductor y proceder a su reducción a metal, funcionando así como pequeños hornos muy sencillos y rudimentarios. La masa escoriácea que se forma quedaría adherida a las superficies internas del recipiente, en ocasiones formando pequeñas bolitas de metal en su interior, siendo necesario proceder a su fragmentación para poder extraerlas y triturarlas, con el fin de recuperar el metal obtenido (Rovira y Ambert 2002). Este modelo tecnológíco explicaría así la falta de evidencias de escorias y de hornos.

En los contextos metalúrgicos del Sureste, como por ejemplo Almizaraque (Delibes et al. 1989 y 1991) o Los Millares (Hook et al. 1991; Molina y Cámara 2006), se han documentado numerosos fragmentos de vasijas de reducción con espesas capas de escorificación adheridas en la superficie interna de los recipientes que han aportado evidencias importantes sobre el uso de este tipo de recipientes en la reducción del cobre. En términos generales, estas vasijas suelen presentar formatos similares a los recipientes de uso doméstico, con morfologías que recuerdan formas abiertas como platos, fuentes o cuencos, y en los casos donde se ha podido reconstruir íntegramente su forma, presentan diámetros que pueden alcanzar los 45 cm (Renzi 2010; Rovira y Ambert 2002).

En el Suroeste, la tecnología de las vasijas de reducción sólo ha sido documentada en la fase más reciente de la ocupación de Cabezo Juré (Fig. 4), con cronologías radiocarbónicas que la sitúan en la transición del III al II Milenio A.N.E. Durante esta fase, los contextos arqueológicos de Cabezo Juré muestran un cambio radical respecto a la organización especializada de las fases anteriores, dado que la actividad metalúrgica es muy escasa y se desarrolla en un ámbito doméstico mediante la utilización de vasijas de reducción, frente a la ausencia de instrumental tecnológico complejo (hornos, crisoles o toberas) que caracterizaron los momentos precedentes (Nocete 2004 y 2006). Los ejemplares de vasijas de reducción 
documentados en Cabezo Juré presentan formas que podemos adscribir morfológicamente a fuentes o cuencos, mayoritariamente de paredes espesas y bordes ligeramente engrosados, evidenciando adherencias escoriáceas y signos de elevadas alteraciones térmicas, principalmente en sus caras internas.

Por último, otro de los elementos cerámicos asociados a contextos metalúrgicos del III Milenio A.N.E. serían las toberas, instrumentos en forma de tubo, utilizados para facilitar la inyección de aire a presión directamente sobre la combustión, con el fin de incrementar la temperatura interna a través del aumento de oxígeno. Las toberas pueden estar asociadas tanto a las tareas de reducción de mineral en hornos o vasijas de reducción como a las de fundición y refino en crisoles o recipientes de cerámica.

La inyección del aire en las estructuras pirometalúrgicas se consigue mediante la insuflación natural, aprovechando las corrientes de aire mediante el desarrollo de la actividad metalúrgica en lugares con vientos dominantes fuertes, o humana, a través del soplo de boca por una boquilla de material perecedero como una caña, o más frecuentemente mecánica, mediante la ayuda de fuelles (Gómez 1999). Las toberas, por tanto, serían el elemento que estaría en contacto directo con la combustión, haciendo la ligación con la fuente de aire. De hecho, las toberas presentan a menudo signos de haber estado sometidas a altos gradientes térmicos, aunque ningún ejemplar presenta evidencias concretas de adherencias de cobre o escorificaciones en sus extremos, sugiriendo, de este modo, una posición relativamente alejada del mineral/escoria a fundir.

Las toberas identificadas en los contextos analizados en este trabajo presentan, en general, una morfología de tendencia cilíndrica con un tamaño que pueden llegar a alcanzar los $16 \mathrm{~cm}$ y un grosor de hasta $6 / 8 \mathrm{~cm}$, como los casos documentados en Valencina de la Concepción (Inácio et al. 2010) (Fig. 5). Sin embargo, también son conocidos ejemplares de tendencia hiperbólica, como los ejemplares documentados en el yacimiento de La Junta (Nocete 2008) y Cabezo Juré (Nocete et al. 2011). El orificio interno para la inyección del aire, con unos $2 \mathrm{~cm}$ de diámetro máximo, es un elemento de extrema importancia en su efectividad ya que, por la cinética del gas encerrado a presión, cuanto más reducido sea el diámetro de la perforación más rápida será la salida del

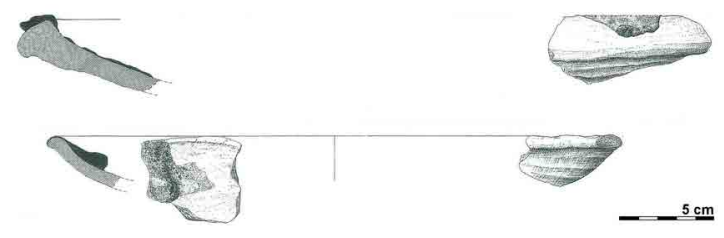

Figura 4. Vasijas de reducción documentadas en la última fase de ocupación de Cabezo Juré.

aire, favoreciendo el aumento de la temperatura de combustión (Gómez 1999; Renzi 2007 y 2010).

A propósito de estos elementos cerámicos cónicos, algunos autores alegan que no se tratan de verdaderas toberas, sino más bien de boquillas de soplado (Renzi 2010: 146) o boquillas protectoras de tubos de soplado (Rovira 2012: 108) que serían acopladas a un tubo de ventilación obtenido con materiales perecederos (por ejemplo una caña) donde sería inyectado el aire a fuerza de pulmón. Por tanto, y por su menor tamaño, la función de estas piezas de cerámica debía ser la de proteger el extremo del tubo de soplado (blowpipes). No obstante, en Cabezo Juré, el registro arqueológico muestra la presencia de toberas asociadas a orificios de anclaje a las paredes del horno mediante lajas de interrupción. Esta tecnología de ventilación asistida mediante toberas de gran tamaño revela inequívocamente la existencia de sistemas de propulsión de aire mediante fuelles (Nocete et al. 2011).

Además de los contextos tratados en este trabajo, la presencia de toberas se encuentra igualmente documentada en otras áreas geográficas, como en la provincia de Badajoz, como han señalado las excavaciones arqueológicas en el yacimiento de Sierrecilla (Cruz Berrocal et al. 2006), o en la Extremadura portuguesa, como en el poblado de Vila Nova de São Pedro (Soares 2005) o Pedra do Ouro (Leisner y Schubart 1966), aunque en este último caso presenta morfología cónica. Asimismo, la presencia de toberas con una configuración similar en el otro extremo peninsular, en el pirineo catalán, en el abrigo rocoso de la Bauma de Serrat del Pont (Girona), confirma la extensión de este modelo tecnológico en gran parte de la Península Ibérica durante el III Milenio A-N.E. (Alcalde et al. 1998).

Sin embargo, resulta especialmente importante señalar la ausencia de toberas en contextos del Sureste, a pesar de los amplios registros 

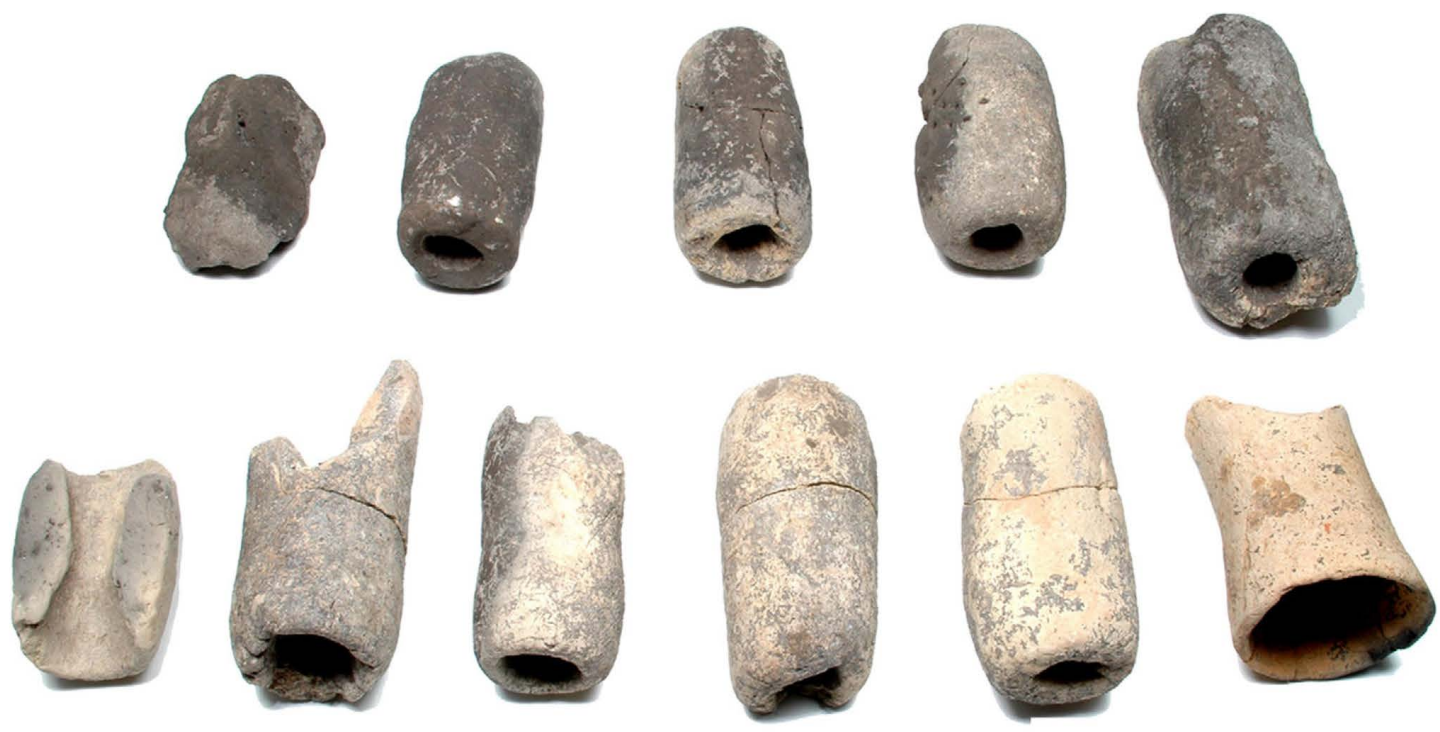

$10 \mathrm{~cm}$

Figura 5. Toberas documentadas en el Barrio Metalúrgico de Valencina de la Concepción.

metalúrgicos de Almizaraque, Los Millares o Cerro Virtud, entre otros (Arribas et al. 1989; Montero 1994). La única excepción parece ser el yacimiento de Las Pilas, donde se han documentado registros metalúrgicos significativos con la presencia de crisoles y toberas similares a los recuperados en Cabezo Juré o Valencina de la Concepción (Cámalich y Martin Socas 1999: 267).

\section{Identificación de las elecciones tecnológicas en sus contextos ${ }^{5}$}

\subsection{La Junta}

En términos generales, los resultados aportados por el análisis petrográfico señalan la utilización de arcillas de origen local, similares a las empleadas en la manufactura de la gran mayoría de los recipientes de uso doméstico, permitiendo concluir la inexistencia de una selección diferenciada de arcillas para la fabricación de cerámicas metalúrgicas. Desde el punto de vista mineralógico y textural, sin embargo, se ha podido discriminar la existencia de dos tradiciones tecnológicas de fabricación (Fig. 6). El primer grupo de muestras, que incluye solamente crisoles, exhibe una matriz arcillosa con una fracción fina rica en cuarzo y un contenido en inclusiones que oscila entre el 18 y $24 \%$. La fracción gruesa, con tamaños inferiores a $1,75 \mathrm{~mm}$, está constituida fundamentalmente por inclusiones de cuarzo y, en menor porcentaje, por fragmentos de rocas metamórficas y metasedimentarias. El análisis químico es congruente con la mineralogía detectada, ya que estas muestras exhiben una composición química con contenidos en $\mathrm{SiO}_{2}$ superiores al $60 \%$.

Otro conjunto de muestras, que incluye la única tobera identificada en este yacimiento, presenta rasgos texturales distintos, ya que exhibe un contenido inferior en inclusiones, oscilando entre el 15 y $18 \%$, aunque estas presentan un mayor tamaño $(>3 \mathrm{~mm})$ y están constituidas fundamentalmente por fragmentos de rocas metamórficas y metasedimentarias. El tamaño relativo de estas inclusiones sugiere un tratamiento de la materia prima mediante la incorporación intencional de desgrasante.

\subsection{Cabezo Juré}

El análisis de la cerámica metalúrgica de Cabezo Juré ha centrado su atención principalmente en la comparación de las distintas elecciones tecnológicas utilizadas en la fabricación de los 
instrumentos utilizados en las tareas de refino (crisoles) y en las tareas de reducción (vasijas de reducción).

La observación petrográfica ha identificado una mineralogía que podemos relacionar con el metamorfismo regional del Complejo Volcánico Sedimentario de la Faja Pirítica, lo que sugiere la utilización de sedimentos procedentes de la alteración superficial de estas rocas y no de arcillas puras. No obstante, desde el punto de vista mineralógico, textural y químico se han observado algunas diferencias entre estas vasijas metalúrgicas.

Los crisoles presentan, en general, una matriz con evidentes signos de vitrificación fruto de los altos gradientes térmicos a que han estado sometidos. La porosidad es elevada, de gran tamaño y constituida mayoritariamente por grietas cuyo desarrollo sugiere la presencia de materia orgánica volatilizada. El contenido en inclusiones oscila entre el $7 \%$ y el $15 \%$. La fracción fina menor que $0,1 \mathrm{~mm}$ está constituida fundamentalmente por cuarzo, mientras que la fracción gruesa está constituida por cuarzo (monocristalino y criptocristalino) y, en menor proporción, fragmentos de roca metamórfica (cuarcitas, filitas, etc.) y sedimentarias (limonitas, areniscas, etc.), opacos y plagioclasas, con tamaños máximos que oscilan entre los 3,2 y $8 \mathrm{~mm}$. El tamaño relativo de las inclusiones en algunas muestras de crisoles sugiere una tendencia al bimodalismo, no descartándose por ello la incorporación intencional de desgrasante (Fig. 7).

En relación a las vasijas de reducción, los individuos estudiados exhiben una matriz con evidentes signos de vitrificación, con porosi- dad formada por poros y grietas, aunque sin la presencia de signos de materia orgánica volatizada como en el caso de los crisoles. El contenido en inclusiones oscila entre el $15 \%$ y el $22 \%$ y está dominado por fragmentos de rocas metamórficas (cuarcitas, filitas, etc.) y metasedimentarias, y menor presencia de fragmentos arcillosos, opacos y cuarzo (monocristalino, policristalino y criptocristalino), con tamaños máximos que oscilan entre 2 y $5,1 \mathrm{~mm}$.

Desde el punto de vista de la composición química, se observan igualmente diferencias significativas entre crisoles y vasijas de reducción, lo que sugiere la utilización de materias primas procedentes de ambientes geológicos distintos y de probables tratamientos tecnológicos diferenciados. Los crisoles presentan contenidos significativamente más elevados en $\mathrm{SiO}_{2}$, Hf, Th, U, Y, Zr y tierras raras ligeras, mientras que las vasijas de reducción presentan valores más elevados principalmente en $\mathrm{Fe}_{2} \mathrm{O}_{3}, \mathrm{MgO}$ y Co.

No obstante, para evaluar la existencia de posibles procesos tecnológicos diferenciados en relación a la cerámica de uso doméstico, se ha procedido al tratamiento estadístico conjunto de la composición química de crisoles, vasijas de reducción y recipientes de uso común. Ello ha permitido observar la existencia de algunas similitudes entre las muestras de cerámica metalúrgica y los recipientes de cerámica común (Inácio 2015). En términos generales, las muestras pertenecientes a crisoles se agregan a un grupo restringido de muestras de cerámica que evidencian un comportamiento homogéneo, mientras que las muestras de vasijas de reducción se encuentran asociadas al
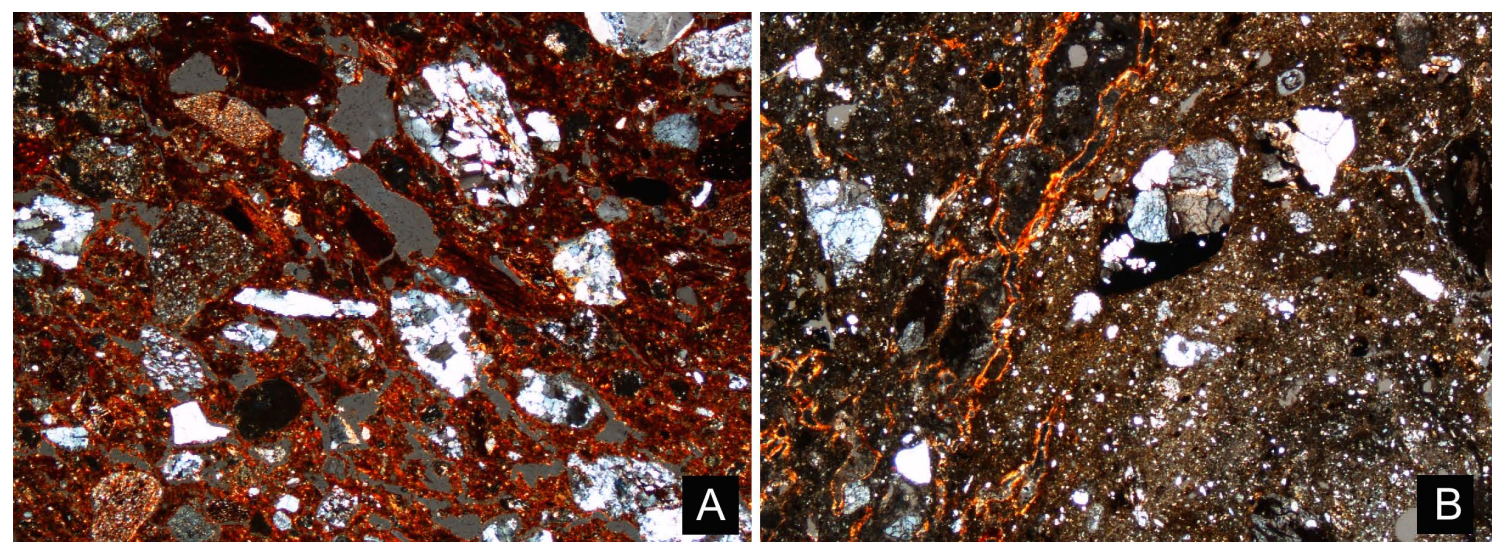

Figura 6. Microfotografías obtenidas en microscopio petrográfico de muestras de toberas y crisoles de La Junta. A: muestra de tobera; B: muestra de crisol. Todas las imágenes han sido obtenidas con nícoles cruzados. Anchura de las imágenes $=7 \mathrm{~mm}$. 

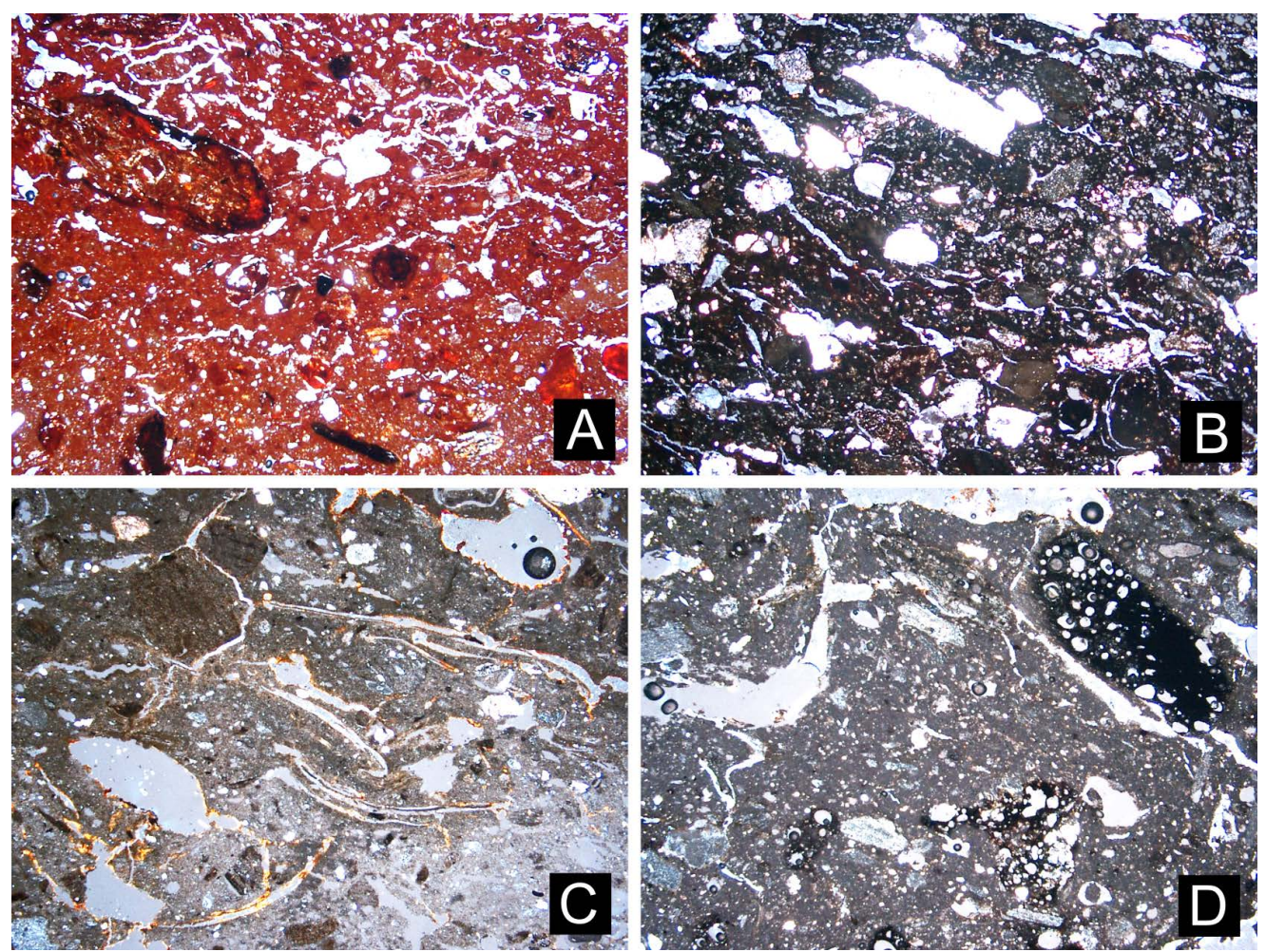

Figura 7. Microfotografías obtenidas en microscopio petrográfico de muestras de vasijas de reducción y crisoles de Cabezo Juré. A: muestra de vasija de reducción con signos de vitrificación; B: muestra de vasija de reducción; C: muestra de crisol con evidencias de materia orgánica volatilizada; D: muestra de crisol con evidencias de vitrificación. Todas las imágenes han sido obtenidas con nícoles cruzados.

Anchura de las imágenes $=7 \mathrm{~mm}$.

conjunto de muestras de cerámica común que aglutina a la mayoría de los recipientes (Figs. 8 y 9 ).

Por todo lo expuesto, los datos aportados por el análisis de los crisoles de Cabezo Juré sugieren que la utilización de arcillas ricas en cuarzo parece haber sido resultado de una elección tecnológica intencional. No obstante, si la utilización preferencial de arcillas con contenidos elevados en sílice puede suscitar algunas dudas interpretativas en relación a su intencionalidad, el tratamiento de la pasta con la incorporación de materia orgánica no puede considerarse, en absoluto, un hecho casual o fortuito.

En lo referente a las vasijas de reducción procedentes de la última fase de ocupación de Cabezo Juré, éstas fueron manufacturadas con arcillas similares a la de la gran mayoría de los recipientes de uso doméstico. Además, tampoco han sido registradas evidencias de un tratamiento diferenciado de la materia prima en relación a la cerámica común, como por ejem- plo la adición de materia orgánica vegetal, lo que sugiere que las vasijas de reducción eran recipientes de uso doméstico que fueron reutilizados durante el proceso metalúrgico para la reducción/fundición del cobre.

\subsection{Valencina de la Concepción}

Las muestras de crisoles y toberas presentan, en general, una matriz limo/arcillosa a margosa, de color gris a marrón, con evidentes signos de alteración térmica. La fracción fina está constituida mayoritariamente por inclusiones de cuarzo, de tendencia subredondeada, con tamaños inferiores a $0,2 \mathrm{~mm}$. En menor proporción, es posible identificar algunos óxidos de hierro, plagioclasas, feldespatos alcalinos y microfósiles (foraminíferos troncoespiralados de tipo globorotalia, así como pequeños gasterópodos). La fracción más gruesa está compuesta también por inclusiones de calcita y caliza micrítica, con tamaños inferiores a $1 \mathrm{~mm}$, que en algunos casos se encuentran totalmente descompuestas por los altos gradientes térmi- 


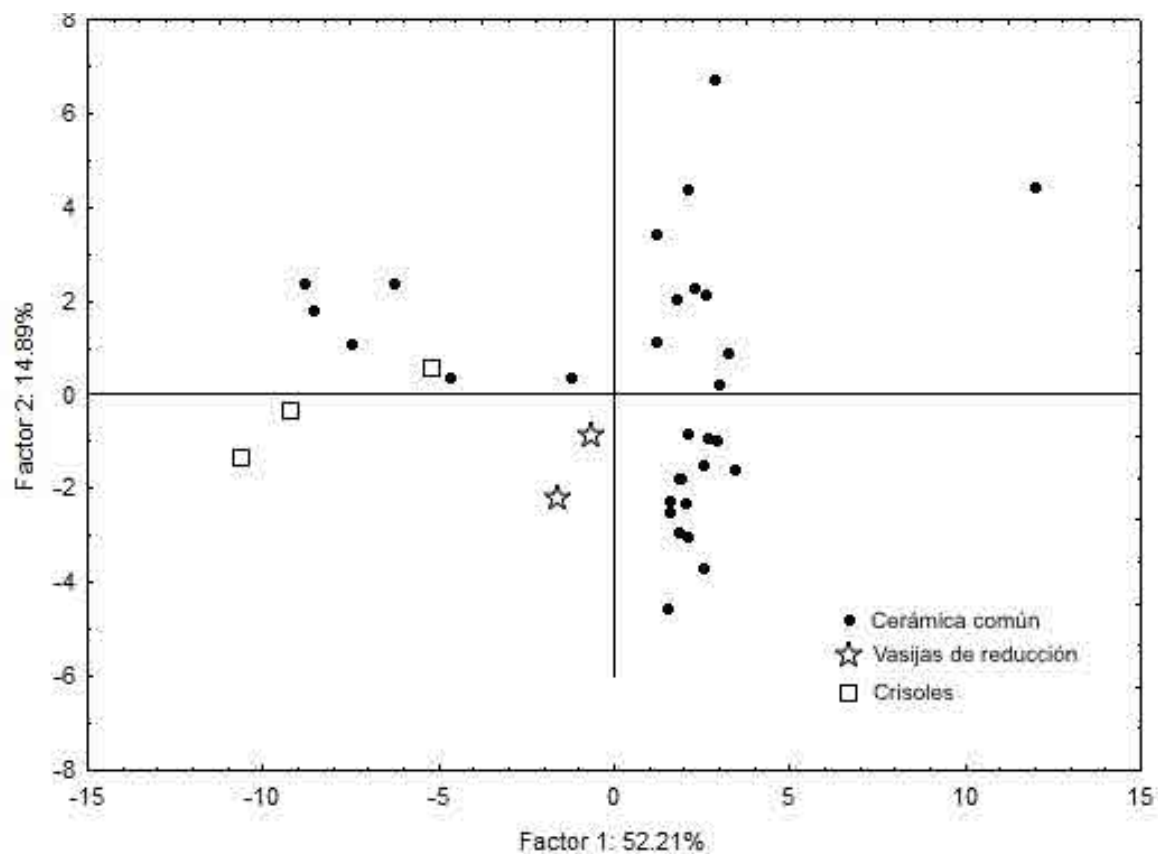

Figura 8. Análisis de Componentes Principales de los resultados del análisis químico de muestras de cerámica y cerámica metalúrgica de Cabezo Juré. Representación según la puntuación en los dos primeros factores.

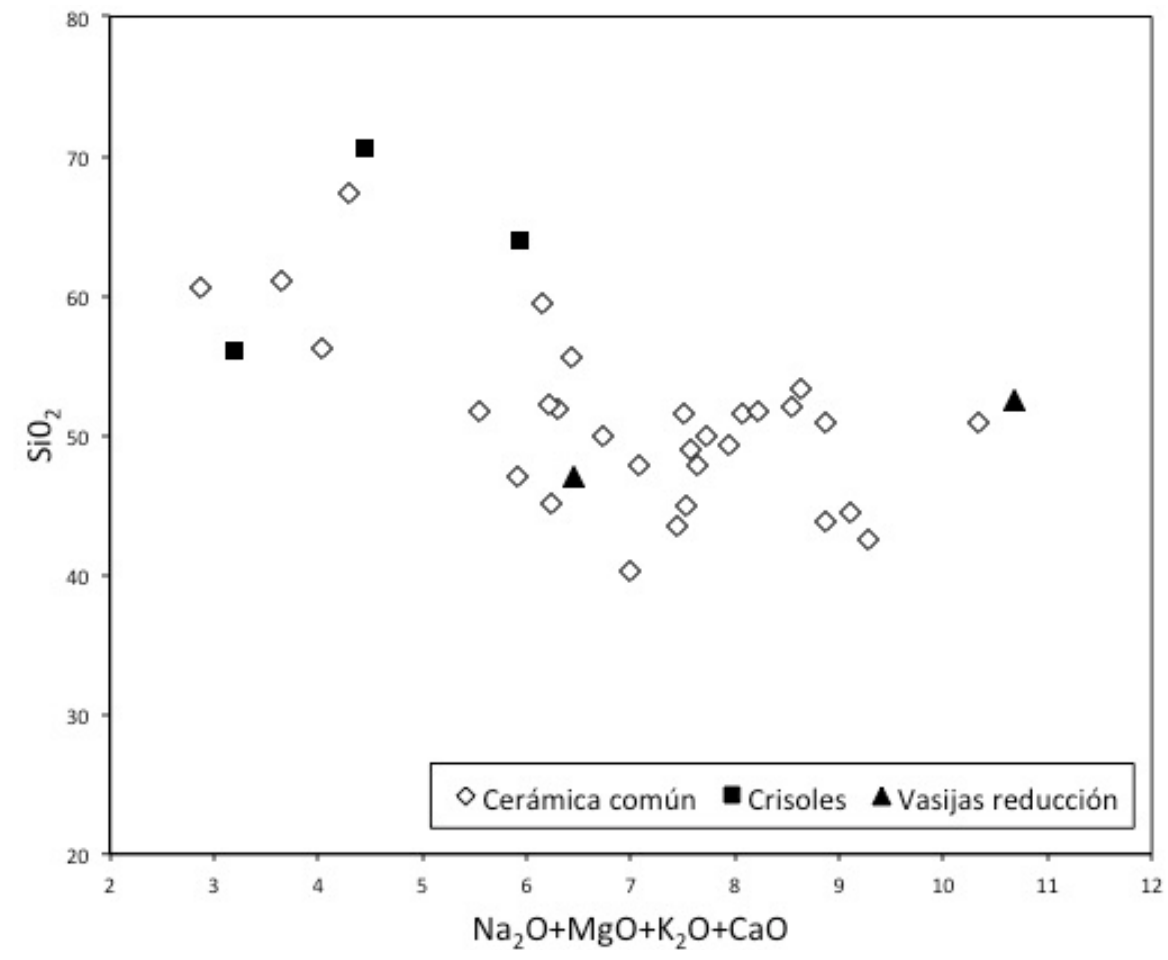

Figura 9. Diagrama binário $\mathrm{SiO}_{2}$ vs. $\mathrm{Na}_{2} \mathrm{O}+\mathrm{MgO}+\mathrm{K}_{2} \mathrm{O}+\mathrm{CaO}$ con la representación de las muestras de cerámica común, crisoles y vasijas de reducción de Cabezo Juré.

cos aque han estado sometidas. Por lo tanto, estos datos sugieren la utilización de arcillas limo-arenosas y margosas con composición mineralógica compatible con las formaciones 

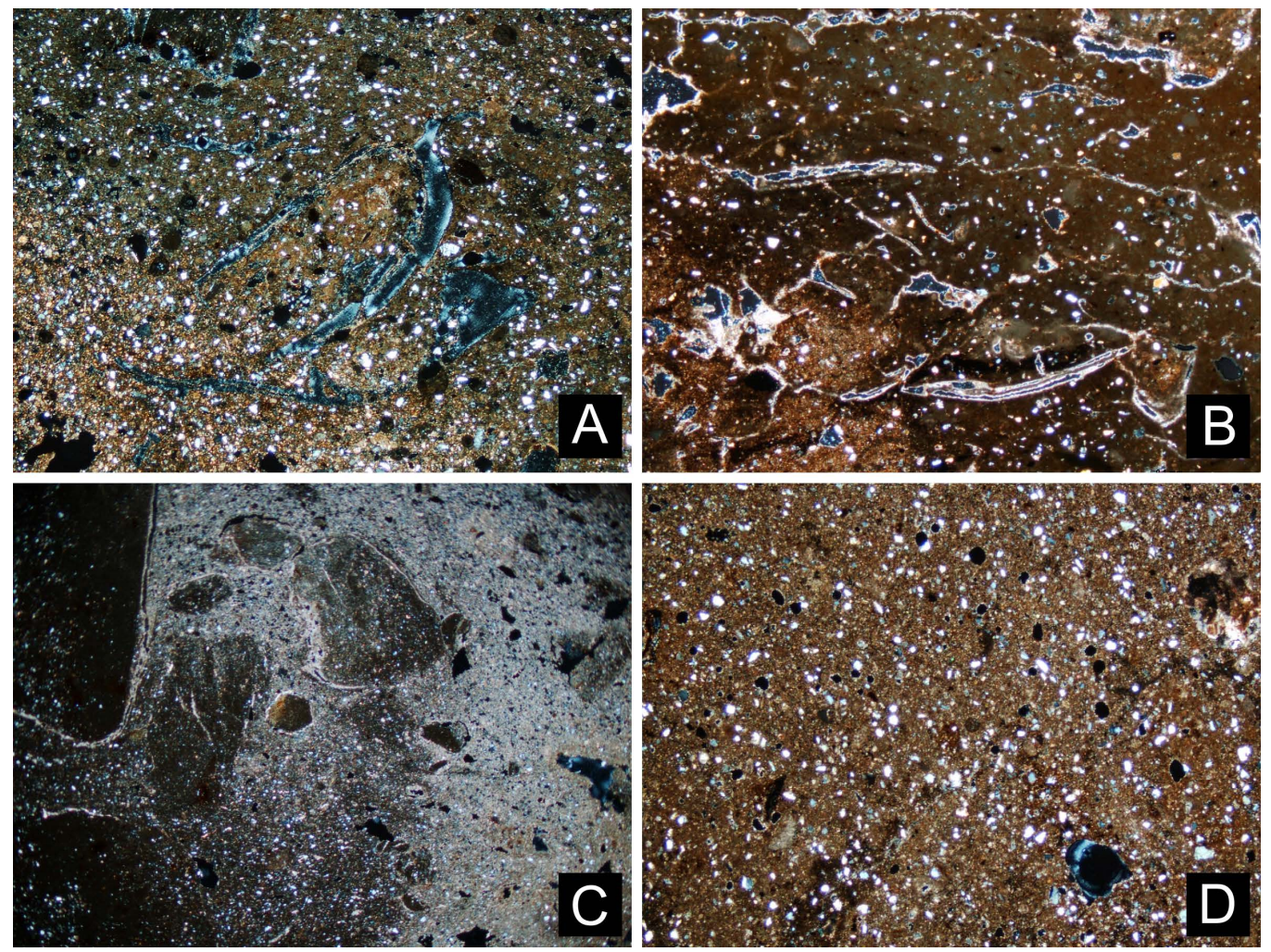

Figura 10. Microfotografías obtenidas en microscopio petrográfico de muestras de crisoles y toberas de Valencina de la Concepción. A y B: muestras de crisoles con evidencias de materia orgánica volatilizada; C: muestra de crisol con posible chamota; D: muestra de tobera.

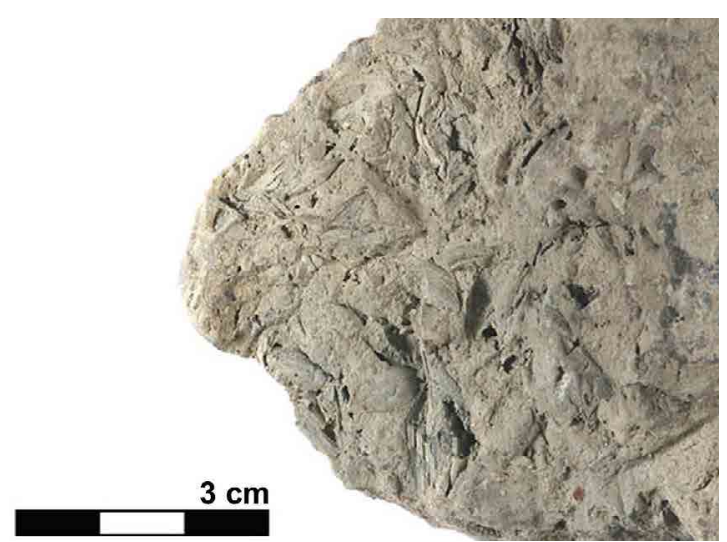

Figura 11. Fotografía del detalle de improntas de materia orgánica vegetal en la pasta de un crisol de Valencina de la Concepción.

miocenas de la depresión del Guadalquivir que forman parte del sustrato geológico donde se ubica el yacimiento.

No obstante, se han identificado rasgos texturales distintos entre estos dos elementos, como la incorporación de materia orgánica y chamota en los crisoles, lo que señala la exis- tencia de elecciones tecnológicos diferenciadas en lo que respecta al tratamiento de la materia prima (Fig. 10). Como ya se había constatado durante el examen macroscópico, donde se han identificado algunos ejemplares de crisoles con restos de materia orgánica incorporada en sus pastas, el examen petrográfico ha demostrado la presencia de restos de materia orgánica no carbonizada completamente y poros formados por su volatilización (Fig. 11). Asimismo, en las muestras de crisoles ha sido posible documentar la presencia de inclusiones arcillosas con tamaños superiores a $5 \mathrm{~mm}$, cuyo análisis de su matriz interna y su tamaño parece indicar que se trata de crisoles molidos (chamota) que fueron deliberadamente añadidos a la arcilla.

Además, las soluciones tecnológicas adoptadas en la manufactura de crisoles y toberas en Valencina de la Concepción contrastan completamente con los procedimientos utilizados en la manufacturas de los recipientes de uso doméstico documentados en los mismos contextos arqueológicos. En términos generales, el análisis arqueométrico de la cerámica de uso común sugiere que para su manufactura 


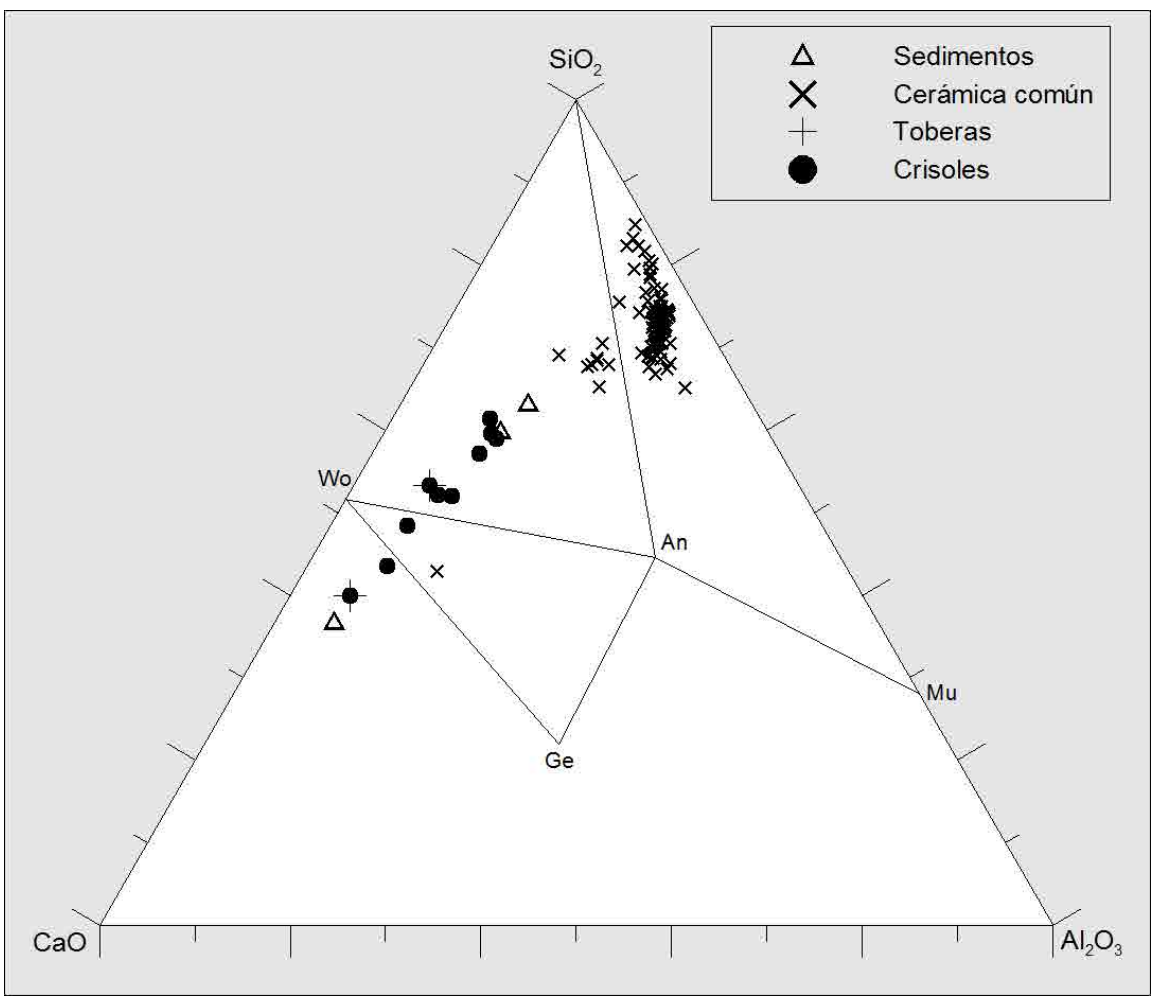

Figura 12. Representación de las muestras de Valencina de la Concepción en el diagrama ternario de equilibrio $\mathrm{SiO}_{2} / \mathrm{CaO} / \mathrm{Al}_{2} \mathrm{O}_{3}$.

han sido utilizadas arcillas no calcáreas, procedentes en su mayoría de un entorno ubicado a más de $12 \mathrm{Km}$ del asentamiento (Fig. 12). Las características químicas y mineralógicas ubican la probable zona de aprovisionamiento al norte de Valencina de la Concepción, en una región dominada por el batolito de la Sierra Norte de Sevilla, donde afloran rocas plutónicas de composición básica a ácida (Inácio 2015). Por el contrario, las arcillas locales han sido utilizadas de forma muy puntual para la fabricación de recipientes de uso cotidiano, lo que sugiere que estas comunidades metalúrgicas, desvinculadas de los ámbitos de producción alfarera, han desarrollado, sin embargo, conocimientos para la fabricación de crisoles y toberas al objeto de responder a su demanda constante $y$, ocasionalmente, de solventar necesidades inmediatas de consumo, para lo que empleaban arcillas similares para fabricar algunos recipientes de cerámica.

\section{Discusión}

El modelo más extendido de explicación de la actividad metalúrgica, y sus implicaciones so- cioeconómicas, define la metalurgia del cobre en el III Milenio A.N.E. de la Península Ibérica como un modelo de producción esencialmente de nivel doméstico, desarrollado a tiempo parcial, con un bajo grado de especialización, donde los sistemas generales de producción de objetos de cobre manifiestan una enorme simplicidad tecnológica y por ello una baja capacidad productiva (Chapman 1996; Gilman 1996; Montero 1994; Rovira 2002 y 2004). La existencia de un conocimiento y de un saber hacer metalúrgico compartido por toda la comunidad, hacía innecesaria la innovación y el desarrollo de los métodos y de las técnicas que se emplean en la producción de objetos de cobre.

Entre otros razonamientos, los autores que han amparado esta propuesta sostienen su argumentación en base a una tecnología del cobre que emplea vasijas de reducción en los procesos de reducción, excluyendo tanto la existencia de hornos metalúrgicos, como la utilización de crisoles para procesos de refino (Rovira 2006).

No obstante, en los últimos años y a partir de los registros arqueológicos documentados en el Suroeste de la Península Ibérica (Nocete 
2001, 2004 y 2006; Nocete et al. 2008 y 2011), se ha sugerido un modelo distinto de desarrollo de la actividad metalúrgica. Así, por ejemplo, la presencia de hornos metalúrgicos asociados a tareas de reducción de minerales y crisoles orientados a trabajos de fundición y refino en Cabezo Juré y en Valencina de la Concepción, y su recurrencia en varios contextos arqueológicos, no expresa la evidencia de una tecnología diferente para la metalurgia del cobre, en la falsa oposición hornos/crisoles y vasijas de reducción, sino una realidad muy compleja que no se encuadra en modelos explicativos monolíticos.

Los resultados aportados por el análisis de la cerámica metalúrgica de Cabezo Juré, La Junta y Valencina de la Concepción ponen de manifiesto la existencia de diferencias significativas en los procesos de fabricación de estos instrumentos, evidenciando comportamientos diferenciados respecto a la selección de la materia prima y a su tratamiento tecnológico, principalmente cuando lo comparamos con la cerámica de uso doméstico.

Los resultados del análisis petrográfico y químico de los instrumentos metalúrgicos de Cabezo Juré y La Junta señalan la utilización de arcillas de origen local, similares a las empleadas en la manufactura de recipientes domésticos. Ello sugiere que en estos dos yacimientos no existió una selección diferenciada de materias primas para la fabricación de cerámicas metalúrgicas. No obstante, en Cabezo Juré, los resultados aportados por el análisis químico sugieren una selección preferencial de arcillas ricas en sílice para la manufactura de los crisoles. La elección de este tipo de arcillas ricas en inclusiones de cuarzo parece haber sido resultado de una selección tecnológica intencional, relacionada con el intento de conferir a las pastas de los crisoles una mayor conductividad (Hein et al. 2008) y aumentar la resistencia al choque térmico (refractariedad) (Tylecote 1982: 240). Además, la incorporación de desgrasante compuesto esencialmente por cuarzo en arcillas poco refractarias puede reducir la contracción de la pasta del crisol al ser sometido a elevadas temperatura (Freestone 1989). La presencia de elementos no plásticos de gran tamaño en la matriz, constituida fundamentalmente por cuarzo y que en algunos casos alcanzan los $5 \mathrm{~mm}$, parece confirmar esta hipótesis.

Este ejemplo no parece haber sido un caso aislado ya que en otros contextos arqueológi- cos peninsulares se ha documentado la utilización preferencial de arcillas de composición más ácida o tratamientos tecnológicos que han incluido la adición voluntaria de desgrasante rico en cuarzo. Así por ejemplo, el análisis arqueométrico de varios crisoles planos del yacimiento de San Blas (Badajoz) ha permitido identificar la utilización preferencial de arcillas de composición ácida, con concentraciones medias en $\mathrm{SiO}_{2}(62,4 \%)$ y $\mathrm{K}_{2} \mathrm{O}(3,2 \%)$ más elevadas que las cerámicas comunes que acumulan valores substancialmente más reducidos de $\mathrm{SiO}_{2}(50,3 \%)$ y $\mathrm{K}_{2} \mathrm{O}(1,6 \%)$ (Polvorinos et al. 2010). En este caso, los resultados del análisis químico señalan la utilización diferenciada de arcillas aptas para soportar altos gradientes térmicos, que han sido enriquecidas con la posible adición voluntaria de arenas silíceas-feldespáticas. Del mismo modo, las observaciones por Microscopio Electrónico de Barrido de algunos instrumentos cerámicos vinculados al proceso metalúrgico de Los Millares (Almería), llevado a cabo por un equipo del Museo Británico, señalan la utilización de arcillas locales ricas en sílice, con valores que oscilan entre el 62 y 71\% (Hook et al. 1991).

Los crisoles de Cabezo Juré observados en microscopio petrográfico se diferencian, además, por presentar evidencias de materia orgánica, lo que hace suponer su incorporación intencional a la arcilla con el objeto de incrementar la porosidad y proporcionar a los crisoles una mayor resistencia al choque térmico (Skibo et al. 1989). Esta solución tecnológica parece haber sido recurrente en los contextos metalúrgicos peninsulares. Además de Valencina de la Concepción, que se comentará más adelante, también en el yacimiento de Peñalosa, con una cronología de la primera mitad del II Milenio A.N.E., se han documentado evidencias de la adición intencional de materia orgánica de origen vegetal a cerámicas metalúrgicas asociadas a formas denominadas de "vasijas hondas" (Moreno et al. 2010).

En lo referente a las vasijas de reducción procedentes de la última fase de ocupación de Cabezo Juré, estas fueron manufacturadas con arcillas similares a los recipientes pertenecientes al grupo mayoritario de recipientes de uso doméstico. Tampoco han sido registradas evidencias de un tratamiento diferenciado de la materia prima en relación a la cerámica común, como por ejemplo la adición de materia orgánica vegetal, sugiriendo la reutilización de recipientes de uso doméstico como vasijas 
para la reducción de mineral, al igual que ocurre en otros contextos del Sureste como Los Millares (Hook et al. 1991) o Almizaraque (Muller et al. 2004).

En Valencina de la Concepción, la manufactura de instrumentos cerámicos vinculados al proceso metalúrgico sugiere la existencia de un modelo aún más complejo al observado en Cabezo Juré. Al contrario que los recipientes de uso doméstico, la utilización de materias primas de origen local para la fabricación de crisoles y toberas define una conducta económica orientada a la eficiencia y a la maximización de los procesos productivos, reduciendo la inversión de trabajo, energía y tiempo en las estrategias de aprovisionamiento de arcillas para la manufactura de estos instrumentos. En un contexto arqueológico donde la producción de objetos de cobre es la actividad económica predominante, la selección de arcillas asociadas a los depósitos calcáreos que forman parte del sustrato geológico del asentamiento, no sólo permitía minimizar el coste su fabricación, sino que, además, posibilitaba focalizar todo el esfuerzo en la manufactura de objetos de cobre.

Junto a ello, las selecciones tecnológicas adoptadas durante la preparación de las materias primas, como la adición de materia orgánica de origen vegetal y de chamota, revelan conocimientos precisos sobre las propiedades térmicas y refractarias de las pastas cerámicas y de los elementos a ellas añadidos. Estas elecciones tecnológicas parecen ser conscientes y deliberadas, con el propósito de incrementar las propiedades refractarias de los instrumentos cerámicos, principalmente los crisoles. El reconocimiento mediante el análisis arqueométrico de procesos productivos complejos y de elecciones tecnológicas que podrían estar directamente relacionadas con determinados conocimientos técnicos, enfatiza aún más la naturaleza especializada de la actividad metalúrgica del barrio metalúrgico de Valencina de la Concepción.

\section{Conclusión}

Con el surgimiento de la metalurgia no sólo nació un nuevo producto - el cobre - y nuevas relaciones sociales de producción - la especialización artesanal - (Nocete 2014), sino que surgieron nuevos procesos de trabajo, nuevas herramientas, nuevos conocimientos sobre las materias primas y nuevos saberes técnicos desconocidos hasta entonces, influenciando por emulación otros sectores artesanales como la alfarería. De ahí la necesidad de evaluar los sistemas tecnológicos y productivos como entidades dinámicas que son influenciados por los contextos sociales y culturales donde se desarrollan.

Desde los inicios de las primeras etapas metalúrgicas, los instrumentos cerámicos han actuado como elementos importantes en el proceso, no sólo por la facilidad de su moldeo sino que, gracias a sus propiedades refractarias, se transformaron en instrumentos de enorme eficacia en las tareas de reducción, fundición y refino. La experiencia y la transmisión de los conocimientos adquiridos por la práctica alfarera durante los milenios precedentes fueron seguramente determinantes para la percepción del comportamiento de las materias primas y del conocimiento de sus propiedades mecánicas y refractarias, lo que acabó permitiendo manufacturar instrumentos de enorme utilidad en el proceso metalúrgico, como fueron los casos de los crisoles y las toberas.

La manufactura de vasijas metalúrgicas, no implicó una ruptura total con los procesos tradicionales de fabricación de recipientes de cerámica, pero determinó la adopción de nuevos procedimientos tecnológicos, no sólo en el tratamiento de la materia prima sino también en la propia confección de la vasija.

Por todo lo expuesto, los datos aportados por el análisis de la cerámica metalúrgica del Suroeste de la Península Ibérica complementan, en parte, los modelos de explicación más extendidos que definen la metalurgia del cobre del III Milenio A.N.E. como una actividad de enorme simplicidad tecnológica, también en las herramientas utilizadas durante el proceso de producción.

Las comunidades metalúrgicas, en general, no han buscado materiales refractarios concretos, sino que los seleccionan dentro de los disponibles en sus entornos inmediatos. No obstante, como ha sido detallado, los datos aportados por la investigación, principalmente sobre los elementos cerámicos asociados al proceso metalúrgico de Cabezo Juré y de Valencina delaConcepción, ponendemanifiesto la existencia de elecciones tecnológicas que evidencian manifiestamente una preocupación por incrementar las propiedades refractarias de estos instrumentos, al objeto de soportar los altos gradientes térmicos a que debían estar 
sometidos durante el proceso metalúrgico. Ello refuta, en parte, los modelos formulados por algunos autores que alegan que las cerámicas metalúrgicas no se diferencian en nada de las comunes en lo que respecta a sus propiedades refractarias (Freestone y Tite 1986; Freestone 1989; Rovira 2012). Ello es evidente, especialmente, en los dos contextos arqueológicos tratados en este trabajo donde la actividad metalúrgica se organizaba en base a modelos más especializados de trabajo. Estas cerámicas metalúrgicas, aún sin entrar en la categoría de refractarias, se diferencian en cuanto a composición, tamaño y tipo de desgrasante empleado en su manufacturación, de las restantes cerámicas de carácter doméstico, sugiriendo también una cierta especialización de esta fase del proceso metalúrgico.

\section{Notas}

5. En este apartado se presentan los resultados generales del análisis arqueométrico realizados a los instrumentos cerámicos de La Junta, Cabezo Juré y Valencina de la Concepción. El protocolo y metodología de análisis aplicado se han basado en el análisis químico composicional (elementos mayoritarios, trazas y tierras raras) por ICP-MS (Inductively Coupled Plasma Mass Espectrometry) e ICP-OES (Inductively Coupled Plasma-Emission Espectrometry) y en el análisis petrográfico mediante la observación de lámina delgada pulida en microscopio óptico de transmisión y reflexión.

\section{Bibliografía}

Alcalde, G.; Molist, M.; Montero, I.; Planagumà, L.; Saña, M.; Toledo, A. (1998): Producciones metalúrgicas en el Nordeste de la Península Ibérica durante el III Milenio Cal AC: El taller de la Bauma del Serrat del Pont (Tortellá, Girona). Trabajos de Prehistoria, 55(1): 81-100. doi:10.3989/tp.1998.v55.i1.318.

Allegretta, I.; Eramo, G.; Pinto, D.; Hein, A. (2014): The effect of temper on the thermal conductivity of traditional ceramics: Nature, percentage and granulometry. Termochimica Acta, 581: 100-109. doi:10.1016/j.tca.2014.02.024.

Arribas, A.; Craddock, P.; Molina, F.; Rothemberg, B. (1989): "Investigación arqueometalúrgica en yacimientos de las Edades del Cobre y Bronce en el Sudeste de Iberia. Minería y Metalurgia en las antiguas civilizaciones mediterráneas y europeas, vol. I: 71-80.

Bayona, M.R. (2008): La investigación de la actividad metalúrgica durante el III Milenio A.N.E. en el suroeste de la Península Ibérica. La Arqueometalurgia y la aplicación de análisis metalográficos y composicionales en el estudio de la producción de objetos de metal. Archaeopress, Oxford.

Cámalich, Mª.D.; Martín Socas, D. (Dirs.) (1999): El territorio almeriense desde los inicios de la producción hasta fines de la antigüedad. Un modelo: la depresión de Vera y Cuenca del río Almanzora. Consejería de Cultura de la Junta de Andalucía, Sevilla.

Cardoso, J.L.; Caninas, J.C. (2010): Moita da Ladra (Vila Franca de Xira). Resultados preliminares da escavação integral de um povoado calcolítico muralhado. Transformação e Mudança no Centro e Sul de Portugal: o $4^{\circ}$ e o $3^{\circ}$ milénios a.n.e. (V.S. Gonçalves; A.C. Sousa, eds.), Cascais: 65-95.

Chapman, R.W. (1996): "Inventiveness and ingenuity"? Craft specialization, metallurgy, and the west mediterranean Bronze Age". Craft specialization and social evolution: In memory of V. Gordon Childe (B. Wailes, Ed.), University Museum Monograph, 93 / University Museum Symposium series, vol. 6, Philadelphia: 73-83.

Cruz Berrocal, M.; Cerrillo, E.; García, J. (2006): Nuevos datos sobre el Calcolítico de Extremadura: el yacimiento de la Sierrecilla (Santa Amalia, Badajoz). SPAL, 15: 51-70.

Delibes, G.; Fernández-Miranda, M.; Fernández-Posse, Ma.D.; Martín, C.; Rovira, S.; Sanz, M. (1989): Almizaraque (Almería): Minería y metalurgia calcolíticas en el Sureste de la Península Ibérica". Minería y metalurgia en las antiguas civilizaciones mediterráneas y europeas (C. Domergue, Coord.), Ministerio de Cultura, Madrid: 81-96.

Delibes, G.; Fernández-Miranda, M.; Fernández-Posse, Ma.D.; Martín, C.; Montero, I.; Rovira, S. (1991): Almizaraque (Almería., Spain). Archaeometalurgie during the Chalcolithic in the southeast od Iberian Peninsula". Découverte du Métal (J.P. Mohen y Ch. Eleure, Ed.), Picard Edt.: 303-316. 
Freestone, I.C. (1989): Refractory Materials and Their Procurement. Old World Archaeometallurgy. Proceedings of the International Symposium "Old World Archaeometallurgy" (A. Hauptmann; E. Pernicka y G.A. Wagner, Eds.): 155-162.

Freestone; I.C.; Tite; M.S. (1986): Refractories in the Ancient and Preindustrial World. Hight-Technology Ceramics. Past, Present, and Future. The Nature of Inovation and Change in Ceramic Technology (W.D. Kingery y E. Lense, Eds.), The American Ceramic Society: 35-63.

Gilman; A. (1996): Craft specialization in Late Prehistoric mediterranean Europe. Craft specialization and social evolution: In memory of V. Gordon Childe (B. Wailes, Ed.). University Museum Monograph, 93 / University Museum Symposium series, 6, Philadelphia: 67-71.

Gómez; P. (1996): Hornos de reducción de cobre y bronce en la Pre y Protohistoria de la Península Ibérica. Trabajos de Prehistoria, 53: 127-143. doi:10.3989/tp.1996.v53.i1.409.

Gómez; P. (1999): Obtención de metales en la Prehistoria de la Península Ibérica. BAR International Series 753, Archaeopress, Oxford.

Gonçalves; V.S. (1989): Megalitismo e Metalurgia no alto Algarve Oriental. Uma aproximação integrada. UNIARCH, Lisboa.

Hanning; E.; Gaub; R.; Goldenberg; G. (2010): Metals for Zambujal: experimentally reconstruction a 5000-year-old technology. Trabajos de Prehistoria, 67(2): 287-304. doi:10.3989/tp.2010.v67.i2.

Hein; A.; Müller; N.S.; Day, P.M.; Kilikoglou; V. (2008): Thermal conductivity of archaeological ceramics: The effect of inclusions, porosity and firing temperature. Thermochimica Acta, 480: 35-42. doi:10.1016/j. tca.2008.09.012.

Hunt; M.A. (2003): Prehistoric mining and metallurgy in south west Iberian Peninsula. BAR International Series 1188. Archaeopress, Oxford.

Hunt; M.; Hurtado; V.; Montero; I.; Rovira; S.; Santos; J.F. (2009): Chalcolithic metal production and provenance in the site of San Blas (Cheles, Badajoz). Archaeometallurgy in Europe: 81-92.

Inácio; N. (2015): Alfarería y Metalurgia. Contribución del análisis arqueométrico para el estudio de los patrones de producción, distribución y consumo de cerámica en el Suroeste de la Península Ibérica durante el III Milenio A.N.E. Tesis Doctoral, Universidad de Huelva.

Inácio; N.; Nocete; F.; Nieto; J.M.; Sáez; R.; Bayona; M.R.; Abril D. (2010): Análisis estructural, químico y mineralógico de productos cerámicos asociados a la producción metalúrgica del III Milenio ANE: el caso de Valencina de la Concepción (Sevilla). Actas del VIII Congreso Ibérico de Arqueometría, Teruel: $75-86$.

Hook, D.R.; Freestone, I.C.; Meeks, N.D.; Craddock, P.T.; Onorato, A. (1991): Early production of copperalloys in South-East Spain. Archaeometry, 90 (E. Pernicka; G.A. Wagner, Eds.), Basel, Birkhauser Verlag: 65-76.

Leisner, V.; Schubart, H. (1966): Die Kupferzeitliche Befestigung von Pedra do Ouro/Portugal. Madrider Mitteilungen, 7, Madrid: 9-60.

López, P.M.; Pajuelo, A. (2013): La secuencia ocupacional durante el III milenio ANE en c/ Trabajadores 1418 (Valencina de la Concepción, Sevilla). El asentamiento prehistórico de Valencina de la Concepción (Sevilla). Investigación y Tutela en el 150 aniversario del descubrimiento de La Pastora (L. García Sanjuán; J.M. Vargas; V. Hurtado; T. Ruiz; R. Cruz-Auñón, Eds.), Universidad de Sevilla: 157-169.

Martinón-Torres, M.; Rehren, T. (2014): Technical Ceramics. Archaeometallurgy in Global Perspective (B.W. Roberts y C.P. Thornton, Eds.), Springer: 107-131.

Molina, F.; Cámara, J.A. (2006): Guía del yacimiento arqueológico de Los Millares. Dirección General de Bienes Culturales de la Junta de Andalucía, Sevilla.

Montero, I. (1994): El Origen de la Metalurgia en el Sudeste de la Península Ibérica. Instituto de Estudios Almerienses. Colección de Investigación, $\mathrm{n}^{\circ} 19$. Almería.

Moreno, A. (2000): La Metalurgia de Peñalosa. Proyecto Peñalosa. Análisis Histórico de las Comunidades de la Edad del Bronce del Piedemonte Meridional de Sierra Morena y Depresión Linares-Bailén (F. Contreras, Coord.), Dirección general de Bienes Culturales de la Junta de Andalucía: 167-235.

Moreno, M.A.; Contreras, F.; Renzi, M.; Rovira, S.; Cortés, H. (2010): Estudio Preliminar de las escorias y escorificaciones del yacimiento metalúrgico de la Edad del Bronce de Peñalosa (Baños de la Encina, Jaén). Trabajos de Prehistoria, 67(2): 305-322. doi:10.3989/tp.2010.v67.i2.

Müller, N.S.; Kilikoglou, V.; Day, P.M.; Vekinis, G. (2014): Thermal shock resistance of tempered archaeological ceramics. Craft and science: International perspectives on archaeological ceramics (M. Martinón-Torres, Ed.). Doha, Qatar: Bloomsbury Qatar Foundation: 263-270. 
Müller, R.; Goldenberg, G.; Bartelheim, M.; Kunst, M.; Pernicka, E. (2007): Zambujal and the beginnings of metallurgy in southern Portugal. Metals and Mines: Studies in Archaeometallurgy (S. La Niece, D. Hook y P. Craddock, Eds.), Archetype Publications: 15-26.

Nocete, F. (2001): Tercer Milenio antes de Nuestra Era. Relaciones y contradicciones centro/periferia en el Valle del Guadalquivir. Bellaterra. Barcelona.

Nocete, F. (coord.) (2004): Odiel. Proyecto de Investigación Arqueológica para el análisis del origen de la desigualdad social en el suroeste de la Península Ibérica. Consejería de Cultura, Junta de Andalucía, Sevilla.

Nocete, F. (2006): The first specialized copper industry in the Iberian Peninsula: Cabezo Juré (2900-2200 BC). Antiquity, 80: 646-65. doi: http://dx.doi.org/10.1017/S0003598X00094102

Nocete, F. (coord.) (2008): El yacimiento de La Junta de los Ríos. Monografías de Arqueología no 29. Consejería de Cultura. Junta de Andalucía. Sevilla.

Nocete, F. (2014): Las sociedades complejas (IV y III Milenio cal B.C.) en la Iberia Meridional. Protohistoria de la Península Ibérica: Del Neolítico a la Romanización (M. Almagro-Gorbea, Ed.), Fundación Atapuerca - Universidad de Burgos: 83-94.

Nocete, F.; Queipo, G.; Sáez, R.; Nieto, J.M.; Inácio, N.; Bayona, M.R.; Peramo, A.; Vargas, J.M.; Cruz, R.; Gil-Ibarbucgi, J.I.; Santos, J.F. (2008): The smelting quarter of Valencina de la Concepción (Seville, Spain): the specialised copper industry in a political centre of the Guadalquivir Valley during the Third millennium BC (2750-2500 BC)". Journal of Archaeological Science, 35: 717-732. doi:10.1016/j. jas.2007.05.019.

Nocete, F.; Sáez, R.; Bayona, M.R.; Peramo, A.; Inácio, N.; Abril, D. (2011): Direct chronometry (14C AMS) of the earliest copper metallurgy in the Guadalquivir Basin (Spain) during the Third millennium BC: First Regional Database. Journal of Archaeological Science, 38: 3278-3295. doi:10.1016/j. jas.2011.07.008.

Polvorinos, A.; Hernández, M.J.; Almarza, J.; Forteza, M.; Hurtado, V.; Hunt, M. (2010): Caracterización arqueométrica e hipótesis funcional de "crisoles planos", escorificados procedentes del yacimiento calcolítico de San Blas (Cheles, Badajoz). Actas del VIII Congreso Ibérico de Arqueometría, Teruel: 379-390.

Renzi, M. (2007): Estudio tipológico y funcional de las toberas del yacimiento de La Fonteta (Guardamar del Segura, Alicante), Trabajos de Prehistoria, 64(1): 165-177. doi:10.3989/tp.2007.v64.i1.

Renzi, M. (2010): Vasijas de uso metalúrgico, toberas y moldes. Manual de Arqueometalugia (I. Montero, Coord.), Museo Arqueológico Regional de Madrid: 123-158.

Rovira, S. (1989): Recientes aportaciones para el conocimiento de la metalurgia primitiva en la provincia de Madrid: un yacimiento Campaniforme en Perales del Río (Getafe, Madrid). Actas del XIX Congreso Nacional de Arqueología: 355-366.

Rovira, S. (2002): Metallurgy and society in Prehistoric Spain. Metals and Society (B.S. Ottaway y E.C. Wager, Eds.). BAR International Series 1061. Archaeopress: 5-20.

Rovira, S. (2004): Tecnología metalúrgica y cambio cultural en la Prehistoria de la Península Ibérica. Norba. Revista de Historia, 17: 9-40.

Rovira, S. (2006): Metalurgia de Crisol : la obtención de cobre en la Prehistoria de la Península Ibérica. De Re Metalica, 5: 37-44.

Rovira, S. (2012): Arqueometalurgia experimental en el Departamento de Prehistoria y Arqueología de la U.A.M. Cuadernos de Prehistoria y Arqueología de la Universidad Autónoma de Madrid, 37-38: 105120

Rovira, S.; Ambert, P. (2002): Vasijas cerámicas para reducir minerales de cobre en la Península Ibérica y en la Francia meridional. Trabajos de Prehistoria, 59(1): 89-105. doi:10.3989/tp.2002.v59.i1.

Sáez, R.; Nocete, F.; Nieto, J.M.; Capitán, Ma .A.; Rovira, S. (2003): The extractive metallurgy of copper from Cabezo Juré, Huelva, Spain: Geochemical and mineralogical study of slag dated to the Third Millennium B.C. The Canadian Mineralogist, 41: 637-648. doi: 10.2113/gscanmin.41.3.627.

Sillar, B.; Tite, M.S. (2000): The challenge of "Technological Choices" for materials science approaches in archaeology. Archaeometry, 42(1): 2-20. doi: 10.1111/j.1475-4754.2000.tb00863.x

Simón, J.L. (1996): Utillaje prehistórico del País Valenciano: los crisoles. Acontia, Revista de Arqueología, 2: $39-51$.

Skibo, J.; Schiffer, M.B.; Reid, K.C. (1989): Organic-tempered pottery: an experimental study. American Antiquity, 54(1): 122-146. doi: 10.2307/281335. 
Soares, A.M.M. (2005): A metalurgia de Vila Nova de São Pedro. Algumas reflexões. Construindo a Memória. As colecções do Museu Arqueológico do Carmo (J.M. Arnaud y C.V. Fernandes, coord.), AAP/Museu do Carmo: 179-188.

Soares, A.M.M.; Araújo, M.F.; Cabral, J.M.P. (1994): Vestígios da práctica de metalurgia em povoados calcolíticos da Bacia do Guadiana, entre Ardila e o Chança. (J.M. Campos; J.A. Pérez; F. Gómez, Eds.) Arqueología en el entorno del Bajo Guadiana. Huelva: 165-200.

Tite, M.S.; Kilikoglou, V.; Vekinis, G. (2001): Strength, Toughness and Thermal Shock Resistance of Ancient Ceramics, and Their Influence On Technological Choice. Archaeometry, 43(3): 301-324. doi: 10.1111/1475-4754.00019.

Tylecote, R.F. (1982): Metallurgical crucibles and crucible slags". Archaeological Ceramics (J.S. Olin; A. D. Franklin, eds.), SmithsonianInstitution Press: 231-243. 